\title{
Strategies for Work-Life Balance for Women in the Academic Profession of Sri Lanka
}

\author{
Indumathi Welmilla ${ }^{1}$ \\ ${ }^{1}$ Department of Human Resource Management, University of Kelaniya, Sri Lanka \\ Correspondence: Indumathi Welmilla, Department of Human Resource Management, University of Kelaniya, Sri \\ Lanka. Tel: 947-1681-1169. E-mail: iwelmilla@kln.ac.lk
}

Received: April 5, 2020

doi:10.5539/ass.v16n5p130

\author{
Accepted: April 13, 2020 \\ Online Published: April 30, 2020 \\ URL: https://doi.org/10.5539/ass.v16n5p130
}

\begin{abstract}
Most researchers are investigating work-life balance as a Human Resource Management tool used to attract, motivate and retain skilled employees rather than focusing on how individuals achieve work and personal life satisfaction when engaging work and family roles. This study shifts the focus from the engagement perspective that is highly beneficial for the organization to an enhancement perspective that increases the quality of personal life. This study aimed to explore and describe strategies for the work-family balance that can potentially contribute to the family wellbeing of women in the academic profession in Sri Lanka.

Semi-structured interviews exploring the experiences of work-life balance were undertaken with thirty women lecturers in state universities in Sri Lanka. Data were analyzed using thematic analysis. The findings suggest the following strategies: compartmentalizing and separating roles between work and life, fostering personal relationships, building a professional support system, a better plan schedule, and organization, self-care in terms of personal, physical, and mental health, learning and research-based work environment, effective communication in both domains, and utilization of technology and focus on sacrificing personal life for success. The identified strategies, specifically for the Sri Lankan context and that it does so from the perspective of Sri Lankan women academics.
\end{abstract}

Keywords: Academic profession, Sri Lanka, strategy, women, work-life balance

\section{Introduction}

Work-life balance (WLB) has been identified as a challenging problem for female professionals (Johanim, Fee \& Zati, 2018) because educated women who participated in professional work has been increased more than previously. Thus it has received increased attention from the researchers on WLB over the years (Kossek, Baltes, \& Matthewa, 2011; Valk \& Srinivasan, 2011). The occupational stress impacts the personal lives of academics as well as their professional performance (Bruening, 1983; Pajak \& Blasé, 1989). Fredrickson (2001) developed a theory to explain the effect of positive emotions on WLB and the ability to develop resiliency. The development of a work-family culture that supports and values the integration of employees' work and family lives has become a necessity to reduce work-family mismatch (Thompson, Poelmans, Allen, \& Andreassi, 2007). However, balancing work and personal lives is one of the most challenging aspects of female academicians.

Moreover, WLB research frequently concerns women academicians (Ahemad, Chaudhary, \& Karush, 2013). The recent trend is that women's participation in the academic environment has grown when compared with the last two decades (Punia \& Kamboj, 2013). In terms of the academic environment, Chrisler (1998) identifies the support from family as a necessary factor for scholarly productivity. Peterson (1998) discussed the advantages of being a partner in an egalitarian dual-career relationship in his study. Although more women are working as faculty members, few reach the higher ranks among university positions because they have to be responsible for domestic life in addition to work commitments (Michell, 2007).

Moreover, women holding academic positions require attributes of intelligence, knowledge, and skills. However, women academics enjoy less freedom in family life relative to their counterparts who are men (Flores \& Day, 2006). According to Goyal and Arora (2012), most women employees are under pressure to balance responsibilities in their career and family domains. Punia and Kamboj (2013) asserted that women in the teaching profession currently face great challenges in achieving a balance between their professional and 
personal life. In Sri Lank, universities are the largest knowledge-based institutions. Thus university academics are expected to serve the economic development of the country through disseminating their knowledge and expertise by the government (Chandra, 2017). This means university academicians' duty not only for the students but also contributes to the economic development of the country. Even though they are professionals, they have family responsibilities and family lives, in addition to their professional workloads. However, Asian women perform many domestic activities such as cooking, cleaning, aged care, and child care rather than Western women (Greenhaus, Parasuraman, Granrose, Rabinowitz, \& Beutell, 1989). Therefore, women who are working as university lecturers face more enormous challenges when balancing their work and personal lives.

This trend exists for Sri Lankan women who are professionals and those who are involved in occupational activities in addition to their traditional family responsibilities. At present, in Sri Lanka, women with a high level of educational qualification, there has been a considerable increase in women entering professional professions (Annual report, 2019) like academics. Consequently, it was important for the Sri Lankan women academics to understand the problem of WLB and to identify the strategies which can be used to reduce or overcome this problem. Women academics' perceptions regarding strategies for WLB that can potentially contribute to work and family satisfaction are, therefore, identified for the purpose of the study.

In light of the above, this study addresses the following research question: What strategies do Sri Lankan women academics perceive as effective in reducing their work-life imbalance? In order to answer the research question, the objective of this study was to identify, from the perspectives of Sri Lankan women academics, strategies for overcoming the work-life imbalance that can potentially contribute to work and family satisfaction.

\section{Literature Review}

\subsection{Work-Life Balance}

Work and family domains are the two most significant aspects of human life. The importance of WLB for both employers and employees should be equal to priorities and cannot be overstated (Adisa et al., 2014). The desired balance between both spheres not only enhance job satisfaction, employee performance, and productivity (Lapierre et al., 2008) but also it will improve the employee well- being and family satisfaction (Greenhaus et al., 2003). However, researchers have suggested definitions of the term, WLB is numerous, and a unified description remains elusive (Felstead, Jewson, Phizacklea, \& Walters, 2002). According to Clark (2000), WLB is defined as the extent to which a person is equally engaged and equally satisfied with their works at home and the workplace with the least conflict. This definition reflects that WLB does not mean an equal balance, and it is about adjusting the working patterns to allow employees to combine work with their family responsibilities. In Comparable to Clerk (2000), Higgins, Duxbury, and Johnson (2000) state WLB as an individual perception regards having achieved a satisfactory determination of the multiple demands of work and family domains. In a similar vein, Grzywacz and Carlson (2007) defined this concept as the accomplishment of work and family expectations that are satisfactorily negotiated in the work-family domains. Special characteristics of this definition can be identified, that it moves the construct from the psychological domain into the social without concerning the procedures for fulfilling responsibilities. However, in contrast to these ideas, Voydanoff (2005) explains WLB as a global assessment that kind of effective participation of both domains, when work resources meet family demands and family resources meet work demand. Among a number of definitions, WLB is simply defined as the absence of work-family conflict (Carlson et al., 2013). This definition implies another side of the continuum and this concept that explains the requirement of individuals to perform both domain activities, for instance as husband and wife, parents and relatives, friends, and neighbors in their social life.

Five main models, such as Spillover, Compensation, Segmentation, Instrumental, and Conflict, are used by researchers to explore the relationship between work and non-work activities (Gust, 2002; Zedeck \& Mosier, 1990). Researchers identify that spillover can be both negative and positive (Mridula \& Shailaja, 2015). Negative spillover signifies that if employees are undergoing stress in one domain, they may feel a sense of dissatisfaction even in the other. Positive spillover refers to when an employee is happy and successful in one domain and feels a sense of satisfaction and complacence in the other domain as well (Mridula \& Shailaja, 2015). Furthermore, researchers have reported that this theory most important for the studies related to the psychology of WLB because it is considered that conflicting events and matters in one domain influence how people perceive their satisfaction in the other domain (Mridula \& Shailaja, 2015). The Compensation theory proposes that anything lacking in one domain, in terms of demands or satisfaction, can be made up for from the opposite domain (Gust, 2002). Therefore, this theory explains that employees try to compensate for the absence of satisfaction in one domain (work or home) by competing to find more satisfaction in the other domain.

According to segmentation theory, every domain function behaves independently. Thus, two domains of work 
and life do not affect each other. Therefore, this theory is the opposite of the spillover theory. Further segmentation theory emphasizes that employees' feeling of satisfaction with maintaining the balance between work and family life is gained by disconnecting from one domain while in the other. Finally, the conflict theory 'proposes that with high levels of demand in all spheres of life, some difficult choices have to be made and some conflicts and possibly some significant overload on an individual occur' (Gust 2002). All of these models have one attribute in common: they simply describe WLB and necessity for a balanced life, but they do not go deep into its nature by explaining it. Clark's (2000) border theory gives a framework for attaining a balance.

According to border theory (Clark, 2000) explains how individuals manage work and family domains and the borders between them in order to achieve balance. It conceptualizes work and family as two different, but interactive, environments that people have associated with different rules, emotions, values, thoughts patterns behaviors. Individuals are seen as border - crossers who are managing and negotiating the work and family domains and the borders between them to achieve WLB. The central focus of the theory is that boundaries and links between work and family should be managed in order to establish and maintain a preferred balance.

Many researchers enquired into employee work-life conditions and consequences. Workplaces have also become more diverse with growth in the economy (Presser, 2003) and the increased flexibility of where and when working occurs, which influences workers' home lives and the balance between spheres (Schieman et al., 2009). Employees in non-traditional households have been facing severe difficulties in balancing work and family life. Being the primary caretakers of the home, children, and elders, women face great conflicts between roles in family and work (Higgins, Duxbury, \& Lee, 1992). The United States has been reluctant to adopt national policies requiring employees to limit work hours or to provide benefits to help employees meet their family and work responsibilities (Addison \& Siebert, 1991).

McNamara, Pitt-Catsouphes, Brown, and Matz-Costa (2012), Greenhaus et al. (2011), and Haddock et al. (2006) all suggested that the importance of strategies as the consents of their studies. They found key strategic components in achieving WFB in terms of flexible work arrangements, non-traditional work hours, family/spouse support, career autonomy, working from home, and supportive management. Tremblay (2014) has shown that employees in the workplace and elements that may facilitate or influence the work-life linkage and he used similar variables as Haddock et al. (2006), such as flexible work arrangements, work schedules, work time, support of co-workers and management. Further, his study is used both qualitative and quantitative methodologies in the analysis. The findings of this research study are similar to those of Haddock et al. (2006); that flexible work schedules, management support, and reduced work length time are measures that are encouraging to achieving WLB.

WLB is energetic for individuals' wellbeing, organizations' performance, and a functioning society (Grady, McCarthy, Darcy, \& Kirrane, 2008). Competing demands of work and family domains cause conflict and negatively affect wellbeing (Clark, 2000; Frone, 2000) because career life and personal life are the most important elements of an individual's life. Findings from the literature review show that conflicts caused by work to family and family to work interference between work and family activities lead to reduce family life satisfaction and work satisfaction (Parasuraman \& Greenhaus, 2002). Clark (2000) highlighted that WLB and wellbeing could be achieved the satisfaction of both work and family lives when there is no role conflict.

In today's competitive business life, balancing work, and family life is a challenge faced by many individuals in Sri Lanka (Opatha, 2010). To extend the literature on WLB in the Sri Lankan context, to date, it examined the job engagement, job satisfaction, and coping strategies of WLB (Opatha, 2010). However, in the last decade, a level of awareness has been rising on the need for balancing work-family demands to achieve a balance between the work-life of Sri Lankan women employees. Above mentioned literature has shown that the task of managing work and family lives is common to all nations of society, including Sri Lankan. However, it can be identified that caring for a child, spouse, parent, or workers absent from family responsibilities experience some sort of life imbalance.

The definitions of WLB are not entirely consistent with each other (Allen et al., 2013; Chan, 2008; Greenhaus et al., 2003). Those definitions from diverse perspectives reveal different cultural backgrounds and personal choices. Therefore, the existing literature of WLB considers the degree of their inconsistency. In this study, the researcher considers WLB to represent high work-life satisfaction, including an individual who is happy and practices a satisfactory equilibrium between their multiple roles. This comprehensive definition incorporates the essential phrase, 'work and family satisfaction,' 'satisfactory equilibrium,' and the word 'happy,' all of which have been comprised in prior definitions. Family wellbeing leads to an increase in the happiness of the family. Newland (2015) defined family wellbeing as a multi-dimensional construct that consists of better environmental 
conditions, spirituality, and a well-family functioning network as a whole. Similarly, family wellbeing is influenced by some factors such as physical health, and psychological health of family members, family conflict and harmony, family cohesion, expression of emotions of family members (Chien \& Mistry, 2013). Moreover, Judith et al. (2015) have empirically revealed that wellbeing is mostly associated with family satisfaction and work/ job satisfaction, which related to income, health, and minimum work-family conflict. Clark's (2000) WLB model treats as a multifaceted construct, and since this model clearly and completely exhibits the meaning of WLB. The 'role satisfaction' of Clark's (2000) model that also the researcher used in the current study is very important because this has been applied as dimensions of individuals' perception of WLB.

\section{Methodology}

\subsection{Research Paradigm}

This study attempts to critique and understand the WLB of the women who are working as university lecturers and develop strategies for overcoming the work-life imbalance of them that can potentially contribute to work and family satisfaction. Therefore, the critical theory paradigm is suited to this study as the topic is more inclined towards feminism.

\subsection{Research Approach}

To reach the objectives of the study seeks to understand the WLB experiences of women academics due to the high demands of work and family roles. The data analysis was guided by phenomenological principles utilizing interviews of data. A phenomenological qualitative investigation begins with a topic and research question that has social and personal meaning and significance (Moustakas, 1994), and this study relates to personal sense and experiences. Therefore, phenomenology approaches are based on the paradigm of personal knowledge and subjectivity. Also, it is emphasizing the importance of personal perspective and interpretation. However, the ultimate solution for the study problem is to find out tactics for the work-life imbalance of women in the academic profession by discovering what appears to be the reasons for imbalance rather than finding the reality. Therefore, the phenomenon studies why women can't achieve WLB between work and family domains.

\subsection{Sampling and Participants}

The target population of this study is female university lecturers of Sri Lanka because the study focuses on WLB experiences of Sri Lankan women academics. However, samples for the qualitative inquiry are generally assumed to be selected purposefully to yield cases that are 'information-rich' (Patton, 2002). Thus, for the current study, the researcher selected the purposive sampling technique for collecting data. The main reason for choosing purposive sampling methods was to enable the researcher best to answer the research question focusing on the qualitative approach. Also, the purposive sampling technique involves selecting individuals or groups who have knowledge or experience of the phenomenon of interest (Creswell \& Plano, 2007). Further, availability and willingness to participate and the ability to communicate experiences and opinions articulately is important (Bernard, 2011). Therefore, the selected sample of the women lecturers in state universities, there were certain diverse aspects of their lives in which the researcher was interested, such as ethnicity, culture, age, etc. Table 1 provides the demographic profile of the participants.

Table 1. Demographic profile of the participants

\begin{tabular}{ccc}
\hline Item & Category & Percentage \\
\hline \multirow{4}{*}{ Age } & 20-29 years & 31.6 \\
& 30-39 years & 34.5 \\
& 40-49 years & 28.4 \\
& Over 49 years & 5.5 \\
\hline \multirow{4}{*}{ Position } & Probationary & 12.6 \\
& Confirmed & 19.5 \\
& Senior Lecturer Grade II & 38.3 \\
& Senior Lecturer Grade I & 22.0 \\
Number of & Professor & 07.6 \\
Children & No child & 21.2 \\
& One child & 35.4 \\
& Two children & 33.6 \\
& Three children & 09.0 \\
\hline
\end{tabular}




\section{Data Collection}

The semi-structured face-to-face individual interviews were used as the main mode of investigation. A total of 38 women lecturers were contacted by telephone to request their participation. However, 30 women lecturers agreed to participate, and eight from the initial pool did not participate for personal reasons. An interview schedule was prepared, including date, time, and venue to meet each participant. In addition to this, the researcher prepared a letter, including personal details, the purpose of the study, and an assurance that confidentiality of views expressed will be maintained. A printed copy of the confidential letter was given to each participant before the commencement of the interview. The researcher reached each interview location for about thirty minutes in advance to avoid any delay. At the beginning of the discussions, participants were informed about the interview process and the concept of WLB. Once more, anonymity and confidentiality were assured to all participants.

Also, the need to record the interview was explained, and some respondents had no objection regarding the interview being voice recorded. Some interviews were written manually on the request of participants. The duration of each interview was approximately half an hour. However, manually written interviews lasted approximately one hour. The interview recordings were saved to reflect the interview number. Each interview was transcribed for data analysis. The name of the university and some information were omitted from the transcript to maintain the ethical considerations. In addition to the semi-structured interviews, a written narrative was selected to collect data toward achieving realistic findings of the study, as this provides insight and understanding into the respondents' perceptions. The sample which the researcher selected to conduct interviews was also used as the sample of narrative data collections.

\section{Data Analysis}

The primary method of analysis of the data in this study was thematic analysis. Reicher and Taylor (2005) point out that with qualitative analysis, the researcher needs to be clear and explicit about what they are doing and what they say, as well as to ensure that what they do match up with what they say. Reicher and Taylor (2005) and Riessman (2008) explain that narratives can also be analyzed in different ways, among them thematic analysis. The use of written narratives was appropriate for this study for gathering some kinds of data, as they provided insights into participants' perceptions. Thus thematic analysis technique was also used for this purpose. The six steps suggested by Braun and Clarke (2008) were followed to analyze the data collected. These steps included: (1) Familiarisation with the data: Transcripts were read and re-read a number of times, followed by a writing process as the first step of analysis procedure to gain familiarity. Next, all the participants' transcripts, the depth of content, meanings, and patterns in data were searched; (2) coding: For each interview, a detailed protocol was written summarizing the main statements of participants. The coding was first done because the researcher could thereby identify suitable categories. An independent coder also performed coding to reduce bias (Miles \& Huberman, 2014); ( 3 ) searching for themes: The researcher sorted the codes into potential themes by looking at how different codes could be combined into overarching themes; (4) reviewing themes: The researcher identified certain broad themes and both the researcher and independent coder then refined the thems; (5) defining and naming the themes: During this step of the analysis, core themes were identified; (6) writing up data: As the final step, the analysis was concluded by writing up the themes of the data.

\subsection{Trustworthiness}

The measures of credibility, dependability, confirmability, and transferability can be employed to ensure trustworthiness (Lincoln \& Guba, 1986). In this study, transcribed narratives were sent back to participants for checking, confirmation of what was said, and avoidance of incorrect interpretations (Doyle, 2007; Creswell \& Miller, 2000), then confirmed the member checking. Reflexivity was applied in this study when taking field notes pertaining to data collection and continually reflected in the entire process to ensure that the study was truthful and accurately reported. In this study, an audit trail was established by keeping notes and other documentation providing evidence of the sequences of research methods. This is stored securely for transfer. An audit was maintained, providing key activities undertaken, and explaining each activity in brief. This also ensures the reliability of the study. Moreover, the study made use of an independent coder to code the data with the use of a work protocol to ensure trustworthiness regarding data analysis.

\subsection{Confidentiality and Ethical Considerations}

Participants were provided a consent letter that assured the confidentiality of views expressed. Before the commencement of interviews, participants were briefed on the researcher's personal information as well as the purpose of data collection. The participant had the opportunity to avoid any questions which they did not like to answer or stop the interview at any time during the interview. Further, participants' names were not used, but each participant was referred to by a unique interview number in the data analysis process to maintain anonymity. 
Names of universities (participant workplace) have been omitted in the transcription process.

\section{Findings}

Data were analyzed by manually using thematic analysis, and identified key themes are illustrated in table 2 . Each theme is discussed in detail below.

Table 2. Themes: Strategies for WLB

Themes/ Strategies

compartmentalizing or separating roles of work and life

fostering personal relationships

creating a professional support system

making correct decisions about time and prioritizing

self-care with respect to personal physical and mental health

learning and research-based work environment

effective communication in both domains

utilization of technology

focus on sacrificing personal life for success

Source: Results from the thematic data analysis

\subsection{Themes 1: Compartmentalizing or Separating Roles of Work and Life}

Participants pointed out the importance of knowing and setting boundaries by distinguishing between duties and responsibilities within the domains of work and family. For example, one participant wrote: 'anyone able to separate the duties and responsibilities of two domains, and then she enjoys aspects of both.' (P14). Another said: 'Balancing work and life means when leaving work at the office: work and life are completely separate, and boundaries should be drawn.' (P2). Following are some important phrases, as examples: '[...] involving professionally in the workplace, without forgetting your individual responsibilities at home [...]' (P 11), 'make sure about limitations of any work, because you need to make time for all [...]' (P 5). These phases are reflective of the importance of identifying the correct boundaries to separate the roles of work and life.

\subsection{Themes 2: Fostering Personal Relationships}

Participants mentioned that maintaining a good personal relationship with family members and others is extremely important to reach balance in any domain. Furthermore, they detailed that as a result of strengthening the personal relationship, they can draw support from them when needed. Participant highlighted, 'I share a lot of the household responsibilities and tasks with my husband because we have a very close personal relationship with each other' (P24). Also, they shared the following: '[...] for my family tasks, my husband helps me, the servant helps as well, and my parents help when needed' (P12), the most highly appreciable thing is having family support so that one can concentrate on their profession. However, this support can be gained through other personal relationships. Another participant stated her experience as an example, 'I am lucky enough to have a husband who is happy and willing to help a lot with household chores when I am busy with my professional work.' These contributions, therefore, point to the importance of strengthening personal relationships that lead to winning others' support to achieve WLB.

\subsection{Themes 3: Creating a Professional Support System}

Participants identified that building a professional support system is a possible strategy for coping with work-life imbalance. One participant stated that 'as we are lecturers, everyone can involve or help with others' work when it is needed' (P26). When we have a heavy workload or high work demand, then Professional support is useful to stay balanced. Some other participants' written answers also support this fact. For example, '[...] it easier to face a problematic situation at the workplace when you receive the support of your colleagues [...]' (P13), and 'I think part of the whole balance is to make sure you have enough support from your faculties (P17).

\subsection{Themes 4: A Better Plan, Schedule, and Organization}

Based on participant responses, this theme relates to time management and prioritizing as a strategy of reducing 
the imbalance. Furthermore, they emphasize the two main factors that require effective planning, scheduling, and organization. Thus, the researcher has identified two sub-themes: time management and correct prioritizing.

\subsubsection{Time Management}

Some of the respondents emphasized time management as the written answer of how to manage the balance between work and life domains. One respondent wrote, 'I am managing my WLB, allocating my time strategically to fulfill both spheres' demands' (P8). Some other participants agreed with this; for example, one explained that ' $[\ldots]$ to balance work and life. I recommended that individuals properly manage their time [...]' (P6). The statement, '[ $\ldots]$ balance means dividing one's time between work and non-work related demands without contradicting either side' (P13), was shared by another participant. Similar idea, 'If you don't manage your limited time, the goals that you want to reach will not be attainable'(P5), which was also shared by a participant. These contributions highlighted that to make the correct decision when allocating time between domains work is a strategy for reducing the imbalance.

\subsubsection{Prioritizing}

Some participants suggested the correct decisions should be made in establishing priorities for work. They described the selection of tasks by priority as another possible strategy for WLB. A participant mention, 'You have to establish priorities and have an understanding about what is important to you for achieving WLB' (P18). Another respondent highlighted, 'The key in balance is to set our priorities, sometimes our career has to be a higher priority than family, and some time it may be vice versa' (P12). These inputs showed the necessity of correct decisions for allocating time and prioritizing.

\subsection{Themes 5: Self-care in Terms of Personal, Physical, and Mental Health}

Participants stated that physical and mental health is necessary for WLB. Some participants highlighted the importance of both physical and mental health. Still, a smaller number of lecturers stated that mental health is more important than physical health because of the nature of their profession. Some explanations of participants were, 'If you don't care for your health, you won't be able to fulfill the family task as well as work duties' (P24), '[...] poor physical fitness is a big issue when engaging in family duties' (P3). Focusing, the profession respondents argued that a whole balance is to ensure your wellbeing. Examples, '[...] less stress and less pressure are necessary to promote WLB [...]' (P9), 'I think part of the whole balance is to ensure your wellbeing [...]' (P10), 'I need to balance work and career life in order not to be over-stressed' (P4), 'we work longer hours and don't enjoy life' (P2). These women academics were clearly aware that due attention to physical and mental health is important to achieving WLB.

\subsection{Themes 6: Learning and Research-Based Work Environment}

The participants demonstrated remarkable insight into themselves in stating that, as they are professionals, the importance of developing both individual and career lives. They suggested that a learning and research-based work environment is necessary for meeting career expectations as well as individual WLB. Thus, they emphasized the work environment can help to develop lecturers' teaching skills and research. Participants have explained their experience and ideas on how this type of environment contributes to WLB. Examples: 'To develop a strong research profile in the relevant discipline, this - by which I mean providing enough facilities is the main response from the university' (P5) and 'Top management should pay attention to lecturers' freedom, as they can then handle work demand effectively' (P15). Participants pointed to the importance of career development, 'A sustainable working policy for academic staff should be put forward to carry out research' (P 11). These contributions stress the need for a learning and research-based work environment to satisfy both work and family.

\subsection{Themes 7: Effective Communication in Both Domains}

Another interesting strategy that participants suggested to reduce work-life imbalance is effective communication. Participants pointed out that open communication with each other reflecting actual information and permitting others to understand the situation properly will lead to minimizing conflict. Some quotes of participants were that: 'family discussions are important to me in receiving others' support to balance my heavy workload at home' (P7), '[...] discuss what everyone is doing during the week, how they are doing, do they need to know anything' (P12), 'When my family members know my busy schedule they try to take up some responsibilities and duties at home' (P11), 'I always communicate to my Head about my family situation, how the children are [...]' (P24). Theses inputs revealed that effective communication is important in both domains, which means apart from communicating with the family regarding the work, it may also be necessary to communicate about the family in the work context. 


\subsection{Themes 8: Utilization of Technology}

Respondents' narrative explored that they have more benefit from utilizing the new technology to cover-up duties. Furthermore, they emphasized that when technology is managed effectively, there are so many ways in which it can enhance the working lives, providing people to set appropriate boundaries. All lecturers, given the nature of the profession, have to use new technology, the degree of utilization varies among the individuals. Participants highlighted technology to be highly important for them because of higher studies and research. Moreover, they appreciated its positive impacts as a time-saver, having had a significant bearing on the lives of participants: 'Accessing huge libraries of research help me to do research' ( P24), 'We can acquire knowledge through the internet by accessing websites or library databases' (P22), 'Technology allowed us to do more things online and to deal with more things without having to be physically in the workplace, we felt that it reduced stress and provided balance' (P20), 'Achieving a WLB would be impossible without technology (P16)', '[...] technology can sometimes enable me to be in two places at once, without neglecting either' (P17). These contributions, therefore, point to the importance of technology usage as well as in-depth study of that to implement.

\subsection{Themes 9: Focus on Sacrificing Personal Life for Success}

The participants demonstrated remarkable insight into themselves in stating that, as they are professionals, the importance of developing career lives than personal lives. They suggested that focus on sacrificing personal life for success is necessary for meeting career expectations as well as achieving WLB. Thus, they emphasized more work commitment can help to develop lecturers' work life as well as family life. Participants have explained their experience and ideas on how this strategy contributes to WLB. 'I feel that work (job) is my whole life. We are, so being successful in the workplace is very important to be the happiness of everyone' (P8), 'Most of the time, I do a favor for work responsibility than the family' (P24), 'Achieving a WLB would be impossible without sacrificing some personal interesting (P12)', '[...] Feeling comfortable with the success of career life, I have achieved, I have missed some family duties and responsibilities., But I feel I've achieved good WLB (P6), 'I think a major part of the whole balance is to make sure better career development,' So more commitment should be toward the work role than the family role.' Theses inputs revealed that focus on sacrificing personal life keeps happier in both work and personal lives.

\section{Discussion}

Women in the academic profession may prefer a strong demarcation between work and life as a strategy for achieving WLB. This finding is consistent with Fraenkel and Capstick (2012) in that the strategy of setting clear boundaries permits them to focus on work when at work. This strategy also conforms with the segmentation model, which views work and life as two separate domains (Blunsdon et al., 2006). The finding that separating roles is an important strategy of WLB shares similarities with Rothbard et al. (2005). This finding also supports Edwards and Rothbard (2000), that, in keeping work and family roles separate, individuals may grow fully devoted to one domain at a time. The strategy of separating roles between work and life is the desire for a less permeable border between work and life and segmentation over integration (Clark, 2000). On the other hand, some scholars argue that some working women prefer higher levels of integration among work and life domains and weak work-life borders (Steele \& Gordon, 2006). This contradiction may be due to the nature of the jobs in which women engage. However, it is notable that women in the academic profession who prefer to climb the career ladder seek strong borders and increased segmentation.

Findings revealed that fostering personal relationships is one of the major strategies to achieve WLB. This strategy is consistent with Fraenkel (2012), who mentions that focusing more strongly on a personal support system is a WLB strategy. The personal support system favors high work demand, assisting in the relief of work-related issues such as work stress and exhaustion, resulting in achieving WS (Ferguson et al., 2014). This result is also consistent with past research by Mostert and Van (2006) that suggest that home support for women has an impact on their professional lives and wellbeing, it is also indicated that the support for work is the proper ways to relieve the work or home stress. Furthermore, this finding suggests that academic women with high levels of home or work pressure and who lack family support also experienced dissatisfaction. As a result, women become worried about their home and family members with direct conflict or imbalance.

Fostering personal relationships has been found to increase WLB (Grazywacz et al., 2000), and it is viewed as family support, which is likely to promote family satisfaction. This study finding suggests two ways of support; family support (as the amount of participating in family tasks) and emotional support (as an emotional understanding of the profession and support).

Creating a professional support system shares a similarity with the strategy of focusing on a professional support system and can be seen as a useful factor to help improve work satisfaction and well-being (Carlson \& Kacmar, 
2007). This finding is linked to the suggestions on the importance of team members as a support system in WLB experiences and the role of supervisor support in reducing work-family conflict (Batt \& Valcour, 2003). As a strategy, the professional support which women academics expect can be secured from persons involved in administration. Allan et al. (2013) have shown a negative correlation between work-life conflict and management support for WLB, which is similar to this finding that women academics felt that they received work support from both management and colleagues and so achieved work and family satisfaction.

The WLB strategy of correct decisions about time and prioritization is consistent with Fraenlke and Capstick (2012). He concludes that managing time and prioritizing work, being consciously aware of the value of time, having reasonable expectations regarding an individual's work and family domain responsibilities, and accurate involvement in decision making are important aspects of this decision making. However, this study noted that women academics have different priorities at different stages and situations in their lives. The benefit of this strategy is that academic women's personal lives do not suffer and that quality of life will not be affected. Moreover, this finding is consistent with Greenhaus and Beutell (1985), who suggested that for women employees who had a problem with WLB, time-based role conflicts were the major underlying reason.

As revealed in this study, caring for women's physical and mental health is a solution for work-life imbalance in academia in Sri Lanka. This conforms with Adisa et al., (2014) findings, which indicated that stress and physical unfitness posed a challenge to WLB, even though the study in question focused specifically on women doctors. This finding of the impact of self-care on personal physical and mental health can also be linked to the strategy related to making time for fun and play at home, exercise, hobbies, and simplifying living (Fraenkel \& Capstick, 2012). Interestingly, time spent on health care allows women academics to feel more professionally committed and involved in their duties and responsibilities at work and at home. These findings have shown that the importance of exercise and a healthy lifestyle is a means to achieve quality WLB. Although women academics expected physical health as an important source of life satisfaction, it not only benefited them physically but also provided a necessary mental respite from their roles as academicians, mothers, and wives. Women academics are reputed for working without mental relaxation. Thus taking time to incorporate adequate time to relieve stress is important. The stress of meeting the expectations of the profession as well as personal psychological needs was strongly related to the issue of work-life imbalance. This finding suggests that the availability of the desired working environment and facilities increased the success of the career of women academics. This type of environment or culture may help their learning. Thus, as found in this study, fostering a learning and research-based culture is an important WLB strategy. The reason for considering this strategy as important to the achievement of many milestones in their lives is because their ability to perform professionally, income and financial security all require them to upgrade their publishing and teaching skills. Thus, if learning and research-based culture exist, it will reduce stress and direct them to their aim with mental relaxation. Therefore, women in the academic field highly appreciate this strategy to reduce the work-life imbalance.

Unlike with literature other strategies, there was no evidence in the literature on how to direct learning, and a research-based culture enhances WLB for women academics. However, an introduction of learning and a research-based culture in this profession leads to enhance the WLB of women academics in a manner not previously seen in the literature.

The strategy of regular communication among parties in work and family domains can be linked to the strategy identified by Theunissen et al. (2003). They revealed that communications with each other having the potential to facilitate a better understanding of each other and each person's current situation, and fosters a supportive work-family culture. Also, this finding can be linked to an argument by Roman et al. (2016) that purposeful communication is inclined to eliminate misunderstandings and conflict. In particular, effective communication plays a key role for individuals to properly understand themselves and their personal needs in achieving WLB. This finding is also consistent with Quick et al. (2004), who suggested that effective communication is needed for individuals to understand themselves, their personal needs actively, and to communicate with each other effectively. Thus, this study confirmed that effective communication plays a key role in achieving WLB. However, implementing an effective communication strategy to increase WLB will assist individuals in managing the inter-role conflict that exists in both domains.

Based on findings, technological advances such as email, cell phone, internet, and all e- facilities can be beneficial to achieve a better balance of both domains. This suggests the impact of technology on increasing the availability of employees, whether they are physically present at work or not, thus providing a solution to a major concern on time management. However, this finding contradicts the argument that technology takes employees' time and attention away from aspects of their lives outside of work (Mridula \& Shailaja, 2015). As with this study, findings only related to the positive impact of technology not only in the family domain but also 
in the work domain. This finding confirms the growing reliance on technology by academics to accomplish their work without presence. This strategy is helping to save time and develop careers providing facilities such as accessing huge libraries of research and acquiring knowledge through the internet by accessing websites or library databases. Thus this strategy directly influences WLB because time and career progress are major factors that affect the WLB of the women academics.

This study shows that technology is a matter of convenience. It has more of a positive impact than negative towards WLB. New technology has provided more flexible work practices and increased speed of work, clear and correct action, and decision making, all of which are solutions to the heavy workload in the workplace, and therefore has generally been found to impact WLB positively.

However, some studies reviewed the technology impacts on WLB but did not address how its effects on the lecturer profession. Therefore, this finding is open to confirmation by the emergence of new contributions to literature and indicates that women academics use more technology for career duties and career development, which in turn helps them to achieve WLB. Thus, current findings support the view that the use of new technology increases academic women's WLB and enables successful engagement in multiple roles.

Another interesting finding from this study is that women academics have indicated that they have a strong personal belief in WLB and are happy to sacrifice their family or personal lives for work with the aim of career success. In addition to that, they are highly focused on professional development. It is worth noting that women academics are willing to sacrifice their personal lives to develop their careers regardless of age, position, or family situation. An important consideration of this finding is young women academics have recognized this occupation as the turning point of their lives and are fully focused on career success. One explanation for being highly involved in a career is that working rigorously is a sign of commitment to work for career progression. Another explanation of this finding is that women academics consider career development is overall life goals. This view highly contributes to enhancing WLB. They look forward to their career and are confident that hard work will help them achieve their life goals sooner. It indicates women academics' dedication to their profession because they trust they have to build their academic career to reach overall life goals.

Based on the discussion above, it becomes apparent that the findings of this study share similarities with strategies for WLB identified in previous studies in other contexts. However, the significance of this study is identified strategies that will be useful to avoid imbalance specifically within a Sri Lankan context and further identify women in the academic profession. Also, these strategies are proposed from an academic professional's perspective. However, this study makes several contributions to existing research. First, the study results show nine strategies that help to reduce WLB. Secondly, the results offer the first indication about strategies including learning and research-based culture, utilizing new technology and focus on sacrificing personal life for success that is specifically focused on the experience of WLB of women academics in Sri Lankan universities. Finally, this study provides more important contributions not only to WLB literature but also to the specific case of women in the academic profession.

\section{Conclusion}

Based on the study findings, it becomes apparent that some of the strategies share similarities with strategies for WLB identified in another context. However, the strategy of the utilization of technology is understood differently in another context. The significance of this study is that it explored strategies for WFB, specifically within the context of women academics in Sri Lanka. Thus this study identified strategy such as a focus of sacrificing personal life for success, where the academics women's' professional aspect contributed to a more objective approach to the strategies. This strategy, which is proposed from a professional perspective, is a new contribution to WLB.

The theoretical implication of this study is to set the ground for future research. The current study revealed the strategies that are useful to Sri Lankan women in the academic profession to avoid their imbalance of work and family life. These themes comprise the main theoretical contribution of the study and enhance WLB literature specific to the Sri Lankan context.

The results of this study have several practical implications that will be beneficial to individuals, Institutes, administrative officers seeking a deeper understanding of the significance of a WLB and their effects on an individual's satisfaction and university ranks. Family members can also learn from this study because women's WLB depends on family members. Understanding WLB strategies found by this study can help these people to know their roles in the process of achieving women's WLB. As a special occupational group, they have to pay attention to self-development and find opportunities to develop their expertise while maintaining WLB; thus, the result of this study more important to them. Finally, these strategies could facilitate the avoidance of work-life 
imbalance by individual women.

From the institutions' point of view, this study should give administrative officers better insights regarding academicians' WLB. This information should be useful to institutions in developing and implementing relevant requirements for professional-level WLB strategies. Moreover, the research findings are also supportive of the view that institutions need to consider individual differences when they deal with work-life imbalance issues and set interventions to facilitate requirements for WLB. The faculty needs to lead an effort that creates an academic working environment that positively affects employees' personal and professional lives. They should be given opportunities for career development.

As is typical of exploratory studies, the researcher interviewed a limited number of participants, which is 30 , even though that is acceptable for the qualitative study. Also, it should be noted that the cross-sectional design does not support inferences about the stability of women in the academic profession over time. For example, reading a Masters's degree or Ph.D. in career stage could affect the relative importance of work and family domains for a lecturer and lead to changes in WLB. Therefore, the longitudinal studies would add significant insight into understanding individuals' WLB experiences over time. Finally, this study also offers valuable insights into how to assists women in academics to reconcile their work and personal life balance. Offering WLB strategies for women employees is a good starting point to increase the individual's quality of life by helping them achieve WLB.

\section{References}

Addison, J. T., \& Siebert, S. (1991). The Social Charter of the European Community: Evolution and Controversies. ILE Review, 44(4), 507-626. https://doi.org/10.1177/001979399104400401

Adisa, T. A., Gbadamosi, G., \& Osabutey, E. L. C. (2016). Work-family balance: A case analysis of coping strategies adopted by Nigerian and British working mothers. Gender in Management: An International Journal, 31(7), 414-433. https://doi.org/10.1108/GM-01-2016-0010

Ahemad, M., Chaudhary, A., \& Karush, D. K. (2013). A review of the quality of work-life balance for women employees: A case of working women in academics. International Journal of Trends in Economics Management \& Technology (IJTEMT), 2(1), 60-65.

Allen, T. D, Johnson, R. C., Kiburz, K. M. \& Shockley, K. M. (2013). Work-Family Conflict: A Review and Agenda for Future Research. Journal of Personnel Psychology, 66(2), 345-376.

Annual Report. (2019). Central Bank of Sri Lanka.

Batt, R., \& Valcour, P. M. (2003). Human resources practices as predictors of work-life outcomes and employee turnover. Industrial Relations, 42(2), 189-220. https://psycnet.apa.org/doi/10.1111/1468-232X.00287

Bernard, H. R. (2011). Research Methods in Anthropology Qualitative and Quantitative Approaches (5th ed.). Rowman Altamira, New York.

Blunsdon, B., Blyton, P., Reed, K., \& Dastmalchian, A. (2006). International perspectives on the balancing of multiple roles: Work-Life Integration. Macmillan: UK.

Braun, V., \& Clarke, V. (2008). Using thematic analysis in psychology. Qualitative research Psychology, 3(2), 77-101. https://doi.org/doi/10.1191/1478088706qp063oa.

Carlson, D. S., \& Kacmar, K. M. (2000). Work-family conflict in the organization: Do life role values make a difference? Journal of Management, 26(5), 1031-1054. https://doi.org/10.1016/S0149-2063(00)00067-2

Carlson, S. D., Kacmar, M. K., Grzywacz, G. J., Tepper, B., \& Whitten, D. (2013). Work-family balance and supervisor appraised citizenship behavior: the link of positive affect. Journal of Behaviour \& Applied Management, 14(2), 87-106.

Chan, C. K. Y. (2008). Border crossing: Work-life balance issues with Chinese entrepreneurs in New Zealand (Master's thesis). Auckland University of Technology, New Zealand. Retrieved from http://core.ac.uk/download/pdf/56361186.pdf

Chandra, G. (2017). Improving the quality of university education in Sri Lanka: an analysis of Quality Assurance Agency Council's reviews. Sri Lanka Journal of social science, 40(1), 3-15. https://doi.org/10.4038/sljss.v40i1.7497

Chien, N. C., \& Mistry, R. S. (2013). Geographical variations in the cost of living: Associations with the family $\begin{array}{llll}\text { and } \quad \text { child } \quad \text { Child } & \text { Development, } 225 .\end{array}$ https://psycnet.apa.org/doi/10.1111/j.1467-8624.2012.01846.x 
Chrisler, J. (1998). Teacher vs. scholar: Role conflict for women. In L. Collins, J. Chrisler, \& K. Quina (Eds.), Career strategies for women in academe: Arming Athena. Thousand Oaks: Sage.

Clark, S. (2000). Work-family border theory: A new theory of work-life balance. Human Relations, 53, 747-770. https://doi.org/10.1177/0018726700536001

Creswell, J. W., \& Miller, D. L. (2000). Determining validity in qualitative inquiry: Theory into Practice, 39(3), 124-130. https://doi.org/10.1207/s15430421tip3903_2

Creswell, J. W., \& Plano Clark, V. L. (2007). Designing and Conducting Mixed Methods Research. London: Sage Publications Ltd.

Doyle, S. (2007). Member checking with older women: A framework for negotiating to mean. Health Care for Women International, 8, 888-908. https://doi.org/10.1111/j.1467-8624.2012011848.x

Edwards, J. R., \& Rothbard, N. P. (2000). Mechanisms linking work and family: Clarifying the relationship between work and family constructs. Academy of Management Review, 25, 178-199. https://psycnet.apa.org/doi/10.2307/259269

Ferguson, M., Carlson, D., \& Kacmar, K. M. (2014). Flexing work boundaries: The spillover and crossover of workplace support. Personnel Psychology, 68, 581-614. https://doi.org/10.1111/peps.12084

Flores, M. A., \& Day, C. (2006). Contexts that shape and reshape new teachers' identities: A multi-perspective study. Teaching and Teacher Education, 22, 219-232. https://doi.org/10.1016/j.tate.2005.09.002.

Fraenkel, P., \& Capstick, C. (2012). Contemporary two-parent families: Navigating work and family challenges. In F. Walsh (Ed.), Normal family processes (4th ed.) (pp. 78-101). New York: Guilford.

Fredrickson, B. L. (2001). The role of positive emotions in positive psychology. The broaden-and-build theory of positive emotions. American Psychologist, 56, 218-226. https://doi.org/10.1037/0003-066X.56.3.218

Frone, M. R. (2000). Interpersonal conflict at work and psychological outcomes: Testing a model among young workers. Journal of Occupational Health Psychology, 5(2), 246-255. https://doi.org/10.1037/1076-8998.5.2.246

Goyal, M., \& Arora, S. (2012). Harnessing work: family life balance among teachers in an educational institute. International Journal of Applied Services Marketing Perspectives, 1(2), 170-176.

Grady, G., McCarthy, A., Darcy, C., \& Kirrane, M. (2008). Work-Life Balance: Policies and Initiatives in Irish Organisations. Cork: Oak Tree Press.

Greenhaus, J. H., \& Allen, T. D. (2011). Work-family balance: A review and extension of the literature. In J. C. Quick, \& L. E. Tetrick (Eds.), Handbook of occupational health psychology, 2, 165-183. Washington, DC: American Psychological Association

Greenhaus, J. H., Parasuraman, S., Granrose, C. S., Rabinowitz, S., \& Beutell, N. J. (1989). Sources of Work-Family Conflict among Two-Career Couples. Journal of Vocational Behavior, 34,133-153.

Greenhaus, J. H., \& Beutell, N. J. (1985). Source of conflict between work and family roles. Academy of management: The Academy of Management Review, 10, 76-88.

Greenhaus, J. H., Collins, K. M., \& Shaw, J. D. (2003). The relation between work-family balance and quality of life. Journal of Vocational Behaviour, 63(3), 510-531. https://doi.org/10.1016/S0001-8791(02)00042-8

Grzywacz, J. G., \& Marks, N. (2000). Reconceptualizing the work-family interface: An ecological perspective on the correlates of positive and negative spillover between work and family. Journal of Occupational Health Psychology, 5(1), 111-126. https://psycnet.apa.org/doi/10.1037/1076-8998.5.1.111

Grzywacz, J. G., \& Carlson, D. S. (2007). Conceptualizing work-family balance: implications for practice and research. Advance in Developing Human Resources, 9, 455-471. https://doi.org/10.1177/1523422307305487

Guest, D. (2002). Perspectives on the study of Worl-Life Balance. Social Science Information, 45, 255-279.

Higgins, C., Duxbury, L., \& Johnson, K. L. (2000). Part-time work for women: does it really help balance work $\begin{array}{lllll}\text { and family? Human } & \text { Resource }\end{array}$ https://doi.org/10.1002/(SICI)1099-050X(200021)39:1\%3C17::AID-HRM3\%3E3.0.CO;2-Y

Higgins, C., Duxbury, L., \& Lee, C. (1992). Balancing work and family: A study of Canadian private-sector employees. London, Ontario: National Centre for Management, Research, and Development. University of 
Western Ontario.

Johanim, J., Fee, Y. T., \& Zati, I. T. Z. (2018). Autonomy, workload, work-life balance, and job performance among teachers. International Journal of Educational Management, 32(1), 107-120. https://doi/org/10.1108/IJEM-10-2016-0226

Judith, L. F, Anisa, Z., Chery, J., Rachel, E., \& Helyne, F. (2015). Work, Family, and Well-Being at Midlife: A Person-Centered Approach. Journal of Family Issues, 36(1), 56-86.

Kossek, E. E., Baltes, B. B., \& Matthewa, R. A. (2011). How work-family research can finally have an impact on organizations. Industrial and Organizational Psychology, 4(3), $352-369$. https://doi/org/10.1111/j.1754-9434.2011.01353.x

Lapierre, L. M., Spector, P. E., Allen, T. D., Poelmans, S., Cooper, C. L., O’Driscoll, M. P., Sanchez, J. I., Brough, P., \& Kinnunen, U. (2008). Family -supportive organization perceptions, multiple dimensions of work-family conflict, and employee satisfaction: A test of the model across five samples. Journal of Vocational Behaviour, 73(1), 92-106. https://psycnet.apa.org/doi/10.1016/j.jvb.2008.02.001

Lincoln, Y. S., \& Guba, E. G. (1986). But is it rigorous? Trustworthiness and authenticity in naturalistic evaluation. In D. D. Williams (Ed.), Naturalistic evaluation (pp. 73-78). San Francisco: Jossey-Bass.

Michelle, B. (2007). Absences and silences in the production of work-life balance policies in Canada. Studies in Political Economy, 81(81), 99-127.

Miles, M. B., \& Huberman, A. M. (2014). Qualitative Data Analysis: A methods sourcebook. Johnny Saldaña (3rd ed.). Arizona State University: SAGE Publications, Inc.

Moustakas, C. (1994). Phenomenological research methods. London, Sage, (Good introduction to the phenomenological approach and later part provides helpful examples of the interview-based phenomenological studies.)

Mridula, N. M., \& Shailaja, S. (2015). A qualitative study on the work-life balance of employees working in the private sector. International Journal of Recent Scientific Research, 6(7), 5160-5167.

Newland, L. A. (2015). Family well-being, parenting, and child well-being: pathways to health adjustment. Clinical Psychologist, 19, 3-4. https://doi.org/10.1111/cp.12059.

Opatha, H. H. D. N. P. (2010). Human Resource Management. Colombo, Author Publication.

Pajak, E., \& Blasé, J. J. (1989). The Impact of Teachers' Personal Lives on Professional Role Enactment: A Qualitative Analysis. American Educational Research Journal, 26(2), $283-310$. https://psycnet.apa.org/doi/10.2307/1163034

Parasuraman, S., \& Greenhaus, J. H. (2002). Toward reducing some critical gaps in work-family research. Human Resource Management Review, 12(3), 299-312.

Patton, M. A. (2002) Qualitative Research \& Evaluation Methods (3rd ed.). Thousand Oaks, CA: London: Sage.

Presser, H. B. (2003). Working in a 24/7 economy: Challenges for American families. New York: Russell Sage Foundation.

Punia, V., \& Kamboj, M. (2013). Quality of work-life balance among teachers in higher education Institutions. Learning Community, 4(3), 197-208.

Quick, J. D., Henley, A. B., \& Quick, J. C. (2004). The Balancing Act: At Work and At Home. Organizational Dynamics, 33(4), 426-438. https://psycnet.apa.org/doi/10.1016/j.orgdyn.2004.09.008

Reicher, S., \& Taylor, S. (2005). Dialoguing across divisions: Similarities and differences between traditions. The Psychologist, 18(9), 547-549.

Riessman, C. K. (2008). Narrative methods for the human sciences. Los Angeles, CA: Sage.

Roman, N. V., Schenck, C., Ryan, J., Brey, F., Henderson, N., Lukelelo, N., \& Saville, V. (2016). Relational aspects of family functioning and family satisfaction with a sample of families in the Western Cape. Social Work/ Maatskaplike Werk, 52(3), 303-312. https://doi.org/10.15270/52-2-511

Rothbard, R., Philips, K., \& Dumas, T. (2005). Multiple roles: work-family policies and individual's desires for segmentation. Organizational Science, 16, 243-258.

Schieman, A., Melissa, A. M., \& Paul, G. (2009). Work interferes with life: work-nonwork interference and the influence of work-related demands and resources, American Sociological Review, 74(6), 966-988. 
https://doi.org/10.1177/000312240907400606.

Steel, M. J., \& Gordon, V. N. (2006). Advising in a multigenerational workplace. Retrieved from national Academy Advising Association Clearinghouse of Academic Advising Resources.

Theunissn, B., Vuuren, L. V., \& Visser, D. V. (2003). Communication of job-related information and work-family conflict in dual-career couples. Journal of Industrial Psychology, 29(1), 18-25.

Thompson, C. A., Poelmans, A. Y., Allen, T. D., \& Andreassi, J. K. (2007). On the importance of coping: A model and new directions for research on work and family. Research in Occupational Stress and Well Being, 6, 73-113

Tremblay, D. G. (2014). Quebec's Policies for Work-Family Balance: A Model for Canada? In B. Fox (Ed.), Family Patterns, Gender Relations (4th ed.). Toronto: Oxford University Press.

Van, D. G., Willemsen, T. M., \& Sanders, K. (2006). Reducing work-family conflict through different sources of social support. Journal of Vocational Behavior, 69(3), 462-476. https://doi.org/10.1016/j.jvb.2006.07.005

Voydanoff, P. (2005). Consequences of Boundary-Spanning Demands and Resources for Work-to Family Conflict and Perceived Stress. Journal of Occupational Health Psychology, 10(4), 491-503. https://doi.org/10.1037/1076-8998.10.4.491

\section{Copyrights}

Copyright for this article is retained by the author(s), with first publication rights granted to the journal.

This is an open-access article distributed under the terms and conditions of the Creative Commons Attribution license (http://creativecommons.org/licenses/by/4.0/). 